\title{
OBITUARY
}

\section{CEDRIC KEITH COHEN}

IT is with great regret that we record the death of a well known Australian ophthalmologist. Dr. Cohen died suddenly of a coronary occlusion at his home at Sydney on July 26, 1952, in his 63rd year. He was the eldest son of the late John Cohen, a judge of the District Court of New South Wales and, at one time, speaker of the New South Wales Legislative Assembly.

Born at Brisbane, he was educated at Sydney Grammar School, and subsequently entered into residence at St. Andrew's College within the University of Sydney, graduating M.B. in 1914 and Ch.M. in 1915. After a period as house-surgeon at the Royal Prince Alfred Hospital he enlisted in the R.A.M.C. when a call came from Britain for medical graduates, and served for four years in France. After the armistice he remained in London and was appointed house surgeon at the Royal Westminster Ophthalmic Hospital, Chandos Street. He later returned to Sydney where he built up a successful practice as an ophthalmic surgeon, and was appointed to the staffs of the Sydney and Lewisham Hospitals.

Dr. Cohen relinquished his appointment to Lewisham after some 17 years but continued his association with Sydney Hospital, where he became senior ophthalmic surgeon, and finally consulting ophthalmic surgeon on his retirement from the active staff in 1950 . During this 30 years of devoted service he conducted a big ophthalmic clinic and was most energetic in the interests of the hospital and its patients, his drive and initiative being largely responsible for the improvements made to the ophthalmic department.

He was associated with the examination and post-graduate teaching of students in ophthalmology at the University of Sydney, and on the foundation of the Royal Australasian College of Surgeons was elected a fellow. He was president of the Ophthalmological Society of New South Wales in 1932, and he became a foundation member of the Ophthalmological Society of Australia (B.M.A.). For 23 years he was a member of Legacy, an organization which gives medical, educational, and material aid to the dependants of deceased ex-servicemen, and became chairman of the medical committee.

Dr. Cohen was extremely fond of music and a most entertaining pianist. In any gathering his distinctive and genial personality attracted interest, and the warmth of his nature and his ready humour quickly established friendships. Dr. and Mrs. Cohen will be remembered by many of those who attended the International Congress of Ophthalmology in London in 1950 and by many European ophthalmologists whom they visited about that time. The outstanding impressions which this kindly ophthalmologist leaves with a host of grateful patients and sorrowing friends are those of a character of great benevolence and of a mind active and interested in all things.

Dr. Cohen's first wife died in 1929. He is survived by his widow, and by the daughter (Mrs. Donald Silver of London and Cyprus) and the son, Brian, of his first marriage. To these members of his family we extend our deepest sympathy. 